Check for updates

Cite this: Chem. Sci., 2020, 11, 107

๑ All publication charges for this article have been paid for by the Royal Society of Chemistry

Received 26th September 2019 Accepted 1st November 2019

DOI: $10.1039 / c 9 s c 04860 j$

rsc.li/chemical-science

\title{
Tuning radical interactions in trisradical tricationic complexes by varying host-cavity sizes $\dagger$
}

\author{
Kang Cai, ${ }^{a}$ Yi Shi, ${ }^{a}$ Changsu Cao, ${ }^{b}$ Suneal Vemuri, ${ }^{a}$ Binbin Cui, ${ }^{a}$ Dengke Shen, ${ }^{a}$ \\ Huang Wu, ${ }^{a}$ Long Zhang, ${ }^{a}$ Yunyan Qiu, (D) a Hongliang Chen, (D) a Yang Jiao, ${ }^{a}$ \\ Charlotte L. Stern, ${ }^{a}$ Fehaid M. Alsubaie, ${ }^{\mathrm{C}}$ Hai Xiao, (D)*b Jun Li (iD ${ }^{\mathrm{b}}$ \\ and J. Fraser Stoddart $\mathbb{D}$ *ade
}

\begin{abstract}
Although host-guest pairing interactions between bisradical dicationic cyclobis(paraquat-p-phenylene) $\left(\mathrm{BB}^{2(\cdot+)}\right)$ and the bipyridinium radical cation $\left(\mathrm{BIPY}^{\cdot+}\right)$ have been studied extensively, host molecules other than $\mathrm{BB}^{2(\cdot+)}$ are few and far between. Herein, four bisradical dicationic cyclophanes with tunable cavity sizes are investigated as new bisradical dicationic hosts for accommodating the methyl viologen radical cation $\left(\mathrm{MV}^{\cdot+}\right)$ to form trisradical tricationic complexes. The structure-property relationships between cavity sizes and binding affinities have been established by comprehensive solution and solid-state characterizations as well as DFT calculations. The association constants of the four new trisradical tricationic complexes are found to range between 7400 and $170000 \mathrm{M}^{-1}$, with the strongest one being 4.3 times higher than that for $[\mathrm{MV} \subset \mathrm{BB}]^{3(\cdot+)}$. The facile accessibility and tunable stability of these new trisradical tricationic complexes make them attractive redox-controlled recognition motifs for further use in supramolecular chemistry and mechanostereochemistry.
\end{abstract}

\section{Introduction}

Among the various noncovalent bonding interactions ${ }^{1}$ which have been explored in the context of supramolecular chemistry, radical-radical interactions between conjugated radical cations $^{2}$ and/or anions ${ }^{3}$ are relatively new on the chemical scene. The bipyridinium radical cation $\left(\mathbf{B I P Y}^{{ }^{+}}\right)$is a well-known thermally stable species with a strong tendency to undergo $\pi$ dimerization $^{2 a, 4}$ (pimerization $^{5}$ ) in aqueous or confined media. The dimerization constant, however, is usually relatively low ${ }^{2 a}$ in organic solvents, a property which limits applications in supramolecular chemistry.

Cyclobis(paraquat- $p$-phenylene) $\left(\mathbf{C B P Q T}^{\mathbf{4}}\right)$, also known as the blue-box ${ }^{4+}\left(\mathbf{B B}^{4+}\right)$, in which two BIPY ${ }^{2+}$ units are connected by two $p$-xylylene spacers to produce a rigid, box-like conformation with a centroid-to-centroid distance of $c a$. $6.9 \AA$ A between

${ }^{a}$ Department of Chemistry, Northwestern University, 2145 Sheridan Road, Evanston, IL 60208, USA. E-mail: stoddart@northwestern.edu

${ }^{b}$ Key Laboratory of Organic Optoelectronics \& Molecular Engineering of the Ministry of Education, Department of Chemistry, Tsinghua University, Beijing 100084, China. E-mail: haixiao@tsinghua.edu.cn

'Joint Center of Excellence in Integrated Nano-Systems, King Abdulaziz City for Science and Technology, Riyadh 11442, Kingdom of Saudi Arabia

${ }^{d}$ Institute for Molecular Design and Synthesis, Tianjin University, 92 Weijin Road, Tianjin 300072, China

${ }^{e}$ School of Chemistry, University of New South Wales, Sydney, NSW 2052, Australia $\dagger$ Electronic supplementary information (ESI) available: Full experimental details and characterisation. CCDC 1955702-1955711. For ESI and crystallographic data in CIF or other electronic format see DOI: $10.1039 / \mathrm{c} 9 \mathrm{sc} 04860 \mathrm{j}$ two BIPY $^{2+}$ units, is an excellent host ${ }^{6}$ for accommodating BIPY $^{{ }^{+}}$in its reduced state ${ }^{7}$ to form a trisradical tricationic complex, $\quad[\mathbf{B I P Y} \subset \mathbf{B B}]^{3(\cdot+)}$. This complex enjoys enhanced stability, ${ }^{8}$ on account of the macrocyclic effect, ${ }^{18}$ rendering the radical host-guest recognition motif attractive for templating the formation of mechanically interlocked molecules ${ }^{9}$ (MIMs) which otherwise cannot be made. A striking feature of this radical host-guest complex is that it can be switched (Scheme

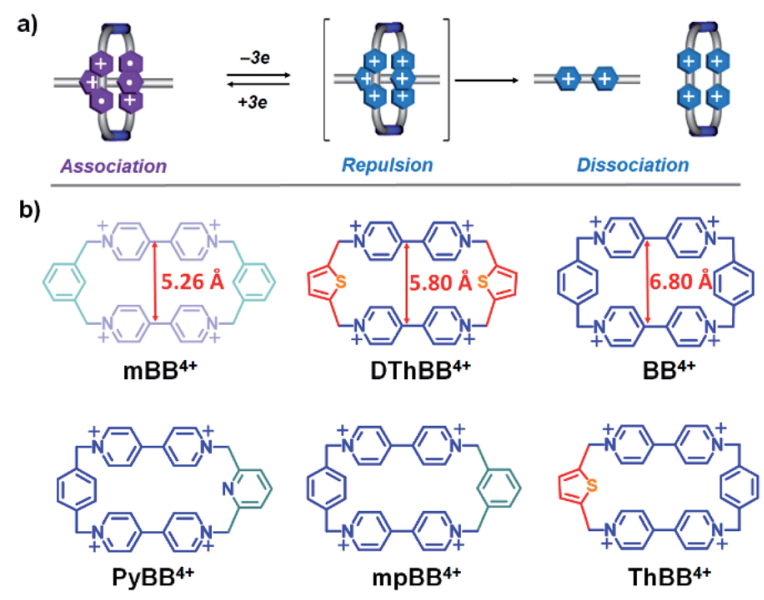

Scheme 1 (a) Graphical representations of redox-controlled attraction and repulsion between the bisradical dicationic cyclophane and BIPY'+; (b) structural formulas of the range of tetracationic cyclophanes. 
1a) from radically based attraction to coulombic repulsion ${ }^{7-9}$ by oxidizing the BIPY ${ }^{++}$units back to their dicationic states, and so providing $^{\mathbf{1 0 , 1 1}}$ a large driving force for the relative motions of component parts inside MIMs. If the coulombic repulsioninduced motions are restricted by the formation of mechanical bonds, BIPY ${ }^{*+}$ radicals with extraordinary stability ${ }^{\mathbf{9 a 1 2}}$ can be produced, affording a new strategy for the design of persistent organic radicals.

Despite the attractive properties and applications of trisradical tricationic complexes, most of the current studies ${ }^{7-11}$

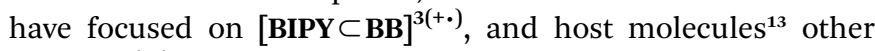
than $\mathbf{B B}^{2(+\cdot)}$ have been little investigated. We have a particular interest in developing new $\mathbf{B B}^{\mathbf{2 ( + \bullet}}$ analogues with smaller cavity sizes, since the decreased separation distance between the two bipyridinium units in cyclophanes is expected to result in increased coulombic repulsion between the guest and different hosts in their oxidized states, which will be beneficial for both the operation of redox-driven molecular machines, such as molecular pumps, ${ }^{\mathbf{1 0 b}}$ and the production of mechanically protected persistent organic radicals. In addition, we have observed $^{8}$ that the centroid-to-centroid distance between two $\mathbf{B I P Y}^{+\cdot 14}$ units in free $\mathbf{B B}^{2(+\cdot)}(6.9 \AA)$ is $c a$. $0.5 \AA$ larger than that $(6.4 \AA)$ present in $\left[\mathrm{BIPY}^{+\cdot} \subset \mathbf{B B}\right]^{3(+\cdot)}$, indicating that a cavity size slightly smaller than that present in $\mathbf{B B}^{2(+\cdot)}$ could be even more favourable for the formation of highly stable trisradical tricationic complexes.

Herein, we describe the syntheses of four tetracationic cyclophanes (Scheme $1 \mathrm{~b})$, one $\left(\mathbf{m p B B} \mathbf{B}^{2+}\right)$ with $m$ - and $p$-xylylene ${ }^{15}$ linkers and three $\left(\mathbf{P y B B}^{2+}, \mathbf{D T h} \mathbf{B B}^{2+}\right.$ and $\left.\mathbf{T h} \mathbf{B B}^{2+}\right)$ with either 2,6pyridinedimethyl $^{\mathbf{1 6}}$ or 2,5-thiophenedimethy ${ }^{17}$ linkers, which retain similar rigidities and conformations to $\mathbf{B B}^{\mathbf{4}}$, while the separation distances between the two BIPY ${ }^{2+}$ units are gradually decreased (Scheme 1b). Complexation of the methyl viologen radical cation $\left(\mathbf{M V}^{+\bullet}\right)$ with these four cyclophanes- $\mathbf{m p B B} \mathbf{B B}^{2+}$, $\mathbf{P y B B}^{2+}, \mathbf{D T h B B}^{2+}$ and $\mathbf{T h B B}^{2+}$-in their reduced states afforded four new trisradical triscationic complexes- $[\mathbf{M V} \subset \mathbf{m p B B}]^{3(+\cdot)}$, $[\mathbf{M V} \subset \mathbf{P y B B}]^{3(+\cdot)},[\mathbf{M V} \subset \mathbf{D T h B B}]^{3(+\cdot)}$ and $[\mathbf{M V} \subset \mathbf{T h B B}]^{3(+\cdot)}$-that were characterised fully by UV-vis-NIR spectroscopy, cyclic voltammetry (CV), and X-ray crystallography. We have discovered that the sizes of the cyclophane cavities exert a large influence on the magnitude of the association constants in MeCN between these four reduced cyclophanes and $\mathbf{M V}^{+\cdot}$.

\section{Results and discussion}

All four tetracationic cyclophanes, namely, $\mathbf{m p B B}{ }^{2+}, \mathbf{P y B B}^{2+}$, DThBB $^{2+}$ and $\mathbf{T h B B}^{2+}$, were prepared-see ESI $\dagger$-by exploiting the tetrabutylammonium iodide (TBAI) catalysed cyclisation, ${ }^{\mathbf{1 8}}$ which involves the reaction of the bis(pyridinium) salt precursor (HS $\cdot 2 \mathrm{PF}_{6}$ ) with 1,4-bis(bromomethyl)benzene or 2,5bis(bromomethyl)thiophene in the presence of $20 \mathrm{~mol} \%$ TBAI in MeCN while stirring under reflux for 4 days. The products were purified by exploiting normal-phase silica gel column chromatography and were obtained in isolated yields (28-52\%) which were higher than that (19\%) obtained for $\mathbf{B B}^{\mathbf{4}^{+}}$under identical conditions, ${ }^{17}$ probably because of the decreased ring strain in the four cyclophanes.
The electrochemical properties of these four cyclophanes, as their $4 \mathrm{PF}_{6}{ }^{-}$salts, were investigated by cyclic voltammetry (CV) in $\mathrm{MeCN}$ at room temperature. The $\mathrm{CV}$ curves of these four cyclophanes plus that of $\mathbf{B B} \cdot 4 \mathrm{PF}_{6}$ showed (Fig. S7†) two reversible reduction waves which are characteristic of $\mathrm{BIPY}^{2+}$ units. The positions of the two reduction waves for the four new cyclophanes are similar to those observed for $\mathbf{B B} \cdot 4 \mathrm{PF}_{6}$, with only slight shifts of no more than $0.12 \mathrm{~V}$ compared with $\mathbf{B B} \cdot 4 \mathrm{PF}_{6}$. These observations are in accordance with our expectations, since the linkers in these cyclophanes should have no significant influence on the electrochemical properties of their BIPY ${ }^{2+}$ units.

The formation of the four new trisradical tricationic complexes were investigated by UV-vis-NIR spectroscopy. Methyl viologen $\left(\mathbf{M V}^{2+}\right)$ was chosen as the representative guest for studying host-guest complexation. The tetracationic cyclophanes and $\mathbf{M V}^{2+}$ were reduced separately in MeCN using $\mathrm{Zn}$ dust to yield suspensions which were filtered to remove the reducing agent. The resulting blue solutions displayed (Fig. 1) similar strong absorptions characteristic of BIPY ${ }^{{ }^{+}}$units in the range 500-700 $\mathrm{nm}$. When the bisradical dicationic cyclophanes were mixed with 1 equiv. $\mathbf{M V}^{{ }^{+}}$, new broad peaks appeared at around ca. $1100 \mathrm{~nm}$, characteristic ${ }^{8}$ of trisradical tricationic complexes. Hence, despite the different constitutions of the linkers, all four cyclophanes retained their ability to host $\mathbf{M V}^{\mathbf{*}}$ in their reduced states. The association constants $\left(K_{\mathrm{a}}\right)$ for the trisradical tricationic complexes were obtained (Fig. 1) by UVvis-NIR titrations. The absorption changes at ca. $1100 \mathrm{~nm}$ were monitored and matched to $1: 1$ isotherms to give the binding constants (Fig. 1 and Table 1) for all four complexes. In addition, the $K_{\mathrm{a}}$ value for $[\mathbf{M V} \subset \mathbf{B B}]^{3(\cdot+)}$ was found, in a control experiment (Fig. $\mathrm{S} 2 \dagger)$, to be $(3.9 \pm 0.5) \times 10^{4} \mathrm{M}^{-1}$ in agreement with the previously reported ${ }^{8} K_{\mathrm{a}}$ value. For $\mathbf{m p B B}^{2(\cdot+)}$ and $\mathbf{P y B B}^{2(\cdot)}$, which have very similar constitutions and cavity sizes, $K_{\mathrm{a}}$ values of $(8.9 \pm 1.3) \times 10^{3} \mathrm{M}^{-1}$ and $(7.4 \pm 0.6) \times 10^{3} \mathrm{M}^{-1}$ were obtained, respectively. Notably, both the two thiophene-
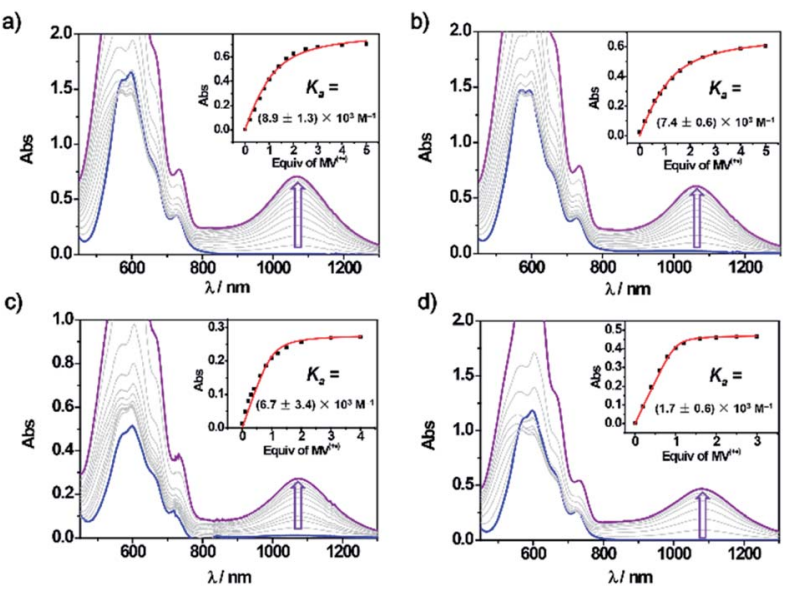

Fig. 1 Vis-NIR spectra (MeCN, 2 mm cuvette) on titrating $\mathrm{MV}^{+\cdot}$ into (a) $\operatorname{PyBB}^{2(\cdot+)}(0.25 \mathrm{mM}) ;\left(\right.$ b) $\mathrm{mpBB}^{2(\cdot+)}(0.25 \mathrm{mM})$; (c) $\operatorname{DThBB}^{2(\cdot+)}(0.20$ $\mathrm{mM})$; (d) $\operatorname{ThBB}^{2(\cdot+)}(0.25 \mathrm{mM})$. The inset shows the change in absorption at $1080 \mathrm{~nm}$ with titration. The curve fitting is highlighted in red. 
Table 1 Summary of cavity sizes $(d)$, binding constants $\left(K_{\mathrm{a}}\right)$ and binding energies $(E)$

\begin{tabular}{lllcccc}
\hline & $d_{1}{ }^{a} \AA$ & $d_{2}{ }^{b} \AA$ & $K_{\mathrm{a}}{ }^{c} \mathrm{M}^{-1}$ & $E_{\text {Exp }}{ }^{d} \mathrm{~kJ} \mathrm{~mol}^{-1}$ & $d_{\text {Calc }^{e}}$ & $E_{\text {Calc }^{f}} \mathrm{~kJ} \mathrm{~mol}^{-1}$ \\
\hline BB & 6.80 & 6.90 & $39000 \pm 5000$ & -26.2 & 6.71 \\
ThBB & 6.10 & 6.72 & $170000 \pm 60000$ & -29.9 & 6.35 & -102.2 \\
DThBB & 5.80 & 6.56 & $67000 \pm 3800$ & -27.5 & -103.7 \\
mpBB & 5.94 & 6.62 & $8900 \pm 1300$ & -22.5 & -100.4 \\
PyBB & 5.65 & - & $7400 \pm 600$ & -22.1 & 5.73 & -95.1 \\
\end{tabular}

${ }^{a}$ Centroid-to-centroid distances of $\mathrm{BIPY}^{2+}$ units in tetracationic cyclophanes according to solid-state structures. ${ }^{b}$ Centroid-to-centroid distances of BIPY $^{++}$units in bisradical dicationic cyclophanes according to solid-state structures. ${ }^{c}$ Binding constants of the trisradical triscationic complexes from vis/NIR titrations. ${ }^{d}$ Binding energies of the trisradical triscationic complexes calculated from vis/NIR titrations. ${ }^{e}$ Centroid-to-centroid distances of BIPY ${ }^{+}$units in bisradical dicationic cyclophanes according to B3LYP-D3-optimized structures solvated in acetonitrile. ${ }^{f}$ B3LYP-D3 method calculated binding energies of the trisradical triscationic complexes.

containing compounds DThBB ${ }^{2(\cdot+)}$ and $\mathbf{T h B B}^{2(\cdot+)}$ display much stronger binding affinities than $\mathbf{m p B B}^{2(\cdot+)}$ or $\mathbf{P y B B}^{2(\cdot+)}$, with their respective $K_{\mathrm{a}}$ values of $(6.7 \pm 3.8) \times 10^{4} \mathrm{M}^{-1}$ and $(1.7 \pm 0.6)$ $\times 10^{5} \mathrm{M}^{-1}$, which are also higher than that $\left(K_{\mathrm{a}}=(3.9 \pm 0.5) \times\right.$ $10^{4} \mathbf{M}^{-1}$ ) of $\mathbf{B B}^{2(\cdot+)}$. These results demonstrate the all-important influence of the linkers on the association constants of these four new trisradical tricationic complexes.

In order to gain a better understanding of the reasons behind the different binding strengths of the dicationic diradical cyclophanes towards $\mathbf{M V}^{{ }^{+}}$, single crystals of the four trisradical tricationic complexes were grown by vapor diffusion of $\mathrm{iP}_{2} \mathrm{O}$ into equimolar solutions in $\mathrm{MeCN}$ of the corresponding bisradical dicationic cyclophanes and $\mathbf{M V}^{++}$in an $\mathbf{N}_{2^{-}}$ filled glovebox. The four crystal superstructures (Fig. 2) of these trisradical tricationic complexes were similar $^{8}$ to that of $[\mathbf{M V} \subset \mathbf{B B}]^{3(\cdot+)}$, and featured the $\mathbf{M V}^{\boldsymbol{}^{+}}$guests encircled by the cyclophanes, with angles between the cyclophane ring planes a)

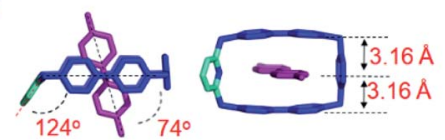

b)

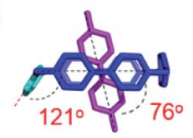

c)
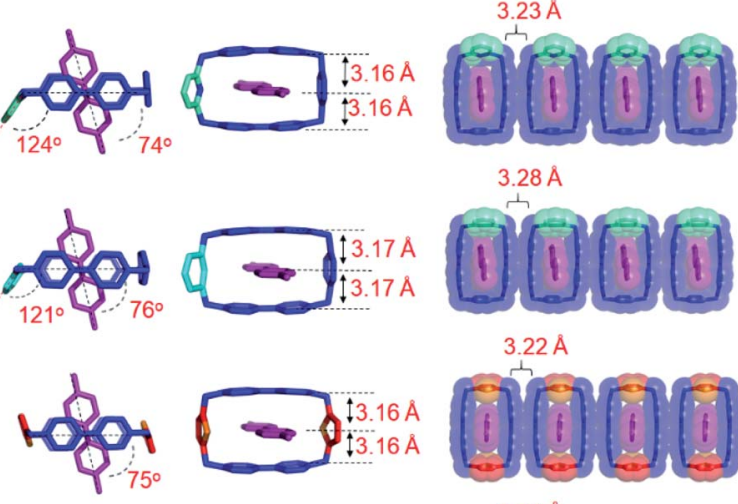

$3.28 \AA$

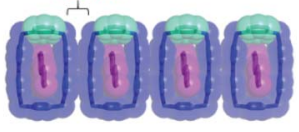

$3.22 \AA$

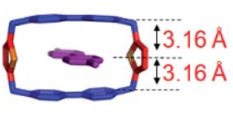

d)

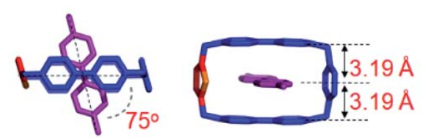

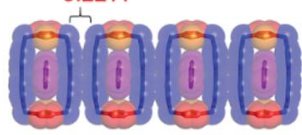

$3.21 \AA$

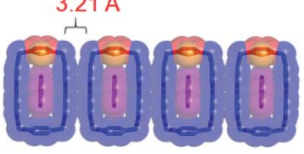

Fig. 2 Solid-state superstructures of trisradical triscationic complexes (a) $[\mathrm{MV} \subset \mathrm{PyBB}]^{3(\cdot+)}$; (b) $[\mathrm{MV} \subset \mathrm{mpBB}]^{3(\cdot+)}$; (c) $[\mathrm{MV} \subset \mathrm{DThBB}]^{3(\cdot+)}$; (d) $[\mathrm{MV} \subset \mathrm{ThBB}]^{3(\cdot+)}$. Left: plan views depicted as tubular representations; middle: perspective views depicted as tubular representations; right: 1D packing of the trisradical complexes depicted as tubular superimposed upon space-filling representations. Hydrogen atoms and disorder in the asymmetric cyclophanes are omitted for the sake of clarity. and the $\mathbf{M V}^{++}$axis of around $75^{\circ}$. Although the cavity sizes for the individual bisradical dicationic cyclophanes are quite different (Table 1) from each other, the distances between the two $\mathbf{B I P Y}^{++}$units in the trisradical tricationic complexes are almost the same, with $\mathbf{M V}^{*+} / \mathbf{B I P Y}{ }^{++}$contact distances (Fig. 2) of 3.16-3.19 $\AA$ and the centroid-to-centroid distance of two cyclophane BIPY $^{+\cdot}$ units of around $6.3 \AA$. This phenomenon is an example of "induced-fit" binding ${ }^{19}$ - i.e., the cyclophanes adjust their conformations (extend or shrink the cavity sizes) to best accommodate $\mathbf{M V}^{++}$guests and thus optimise the radicalpairing recognition interactions. Accordingly, we assumed that the ideal cavity size for accommodating $\mathbf{M V}^{{ }^{*+}}$ guests is around $6.3 \AA$, with smaller or larger sizes resulting in decreased binding affinities towards $\mathbf{M V}^{+}$.

Subsequently, we analysed the crystal structures of the individual cyclophanes in both their oxidised and reduced forms. All four tetracationic cyclophanes readily formed good crystals which were suitable for X-ray crystallographic analyses. The centroid-to-centroid distance (Fig. 3c) between the two $\mathrm{BIPY}^{2+}$ units of the symmetric tetracationic $\mathbf{D T h B B}^{4+}$ is $5.80 \AA$, which is $c a$. $0.5 \AA$ smaller than the "ideal size" of $6.3 \AA$ for binding $\mathbf{M V}^{+\cdot}$ by the bisradical dicationic cyclophanes. $\mathbf{P y B B}^{\mathbf{4 +}}$ featured (Fig. 3b) a trapezoid-like conformation in view of the different separation distances for the $p$-xylylene and 2,6-pyridinedimethyl linkers. Consequently, the distance between the two $\mathrm{BIPY}^{2+}$ units gradually deceases upon going from the $p$ xylylene linker to the $m$-xylylene linker, and the centroid-tocentroid distance (Fig. 4b) of the two BIPY ${ }^{2+}$ units is $c a .5 .65 \AA$ (Fig. 4), which is about $0.65 \AA$ smaller than $6.3 \AA$.
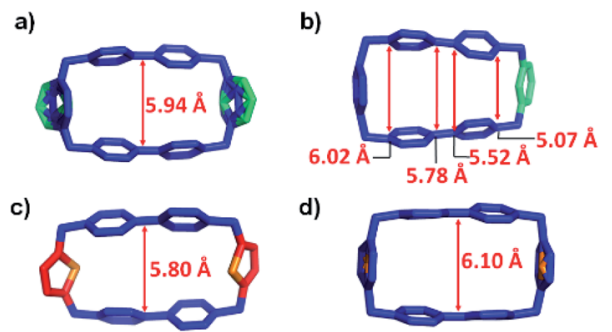

d)

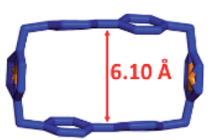

Fig. 3 Solid-state structures of (a) $\mathrm{mpBB}^{4+}$; (b) $\mathrm{PyBB}^{4+}$; (c) $\mathrm{DThBB}^{4+}$ and (d) $\mathrm{ThBB}^{4+}$. Hydrogen atoms are omitted for the sake of clarity. Disorder in the linker parts of the asymmetric cyclophanes $\mathrm{mpBB}^{4+}$ and $\mathrm{ThBB}^{4+}$ is displayed in (a) and (d). 
a)
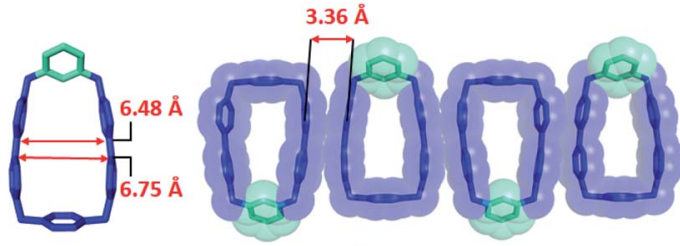

b)
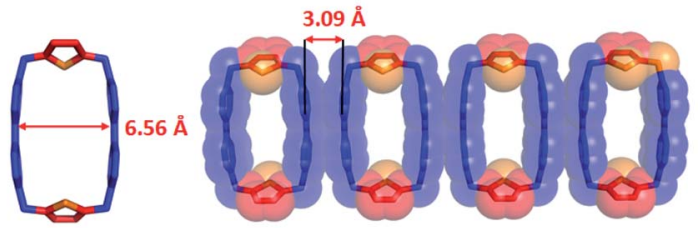

c)

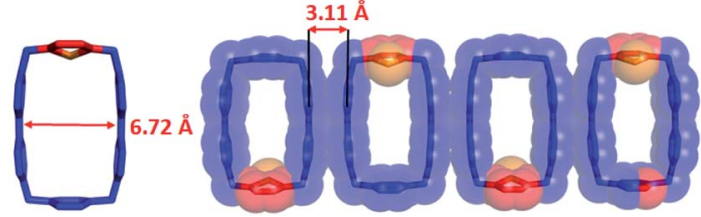

Fig. 4 Solid-state structures of (a) $\mathrm{mpBB}^{2(\cdot+)}$; (b) $\mathrm{DThBB}^{2(\cdot+)}$; (c) $\mathrm{ThBB}^{2(\cdot+)}$. Left: plan views depicted as tubular representations; right: 1D packing of the diradical dicationic cyclophanes depicted as tubular superimposed upon space-filling representations. Hydrogen atoms and disorder in the asymmetric cyclophanes are omitted for the sake of clarity.

The crystal structures (Fig. 3a and d, S8, and S10†) of the other two asymmetric cyclophanes, $\mathbf{m p B B}^{\mathbf{4}^{+}}$and $\mathbf{T h B B}^{\mathbf{4}}$, exhibit disorder in the $m$-xylylene/ $p$-xylylene or $p$-xylylene/2,5-thiophenedimethyl linkers. Consequently, both $\mathbf{m p B B}{ }^{\mathbf{4}^{+}}$and $\mathbf{T h B B}^{\mathbf{4}}$ display a symmetric conformation according to X-ray crystallographic analysis with an apparent centroid-to-centroid distance between $\mathrm{BIPY}^{2+}$ units of 5.94 and $6.10 \AA$, respectively. Since $\mathbf{m p B B}^{4+}$ has an almost identical constitution to that of $\mathbf{P y B B}^{4+}$, the actual conformations and cavity sizes of these two cyclophanes should be similar to each other. Therefore, the apparent centroid-to-centroid distances in $\mathbf{m p B B}^{\mathbf{4}}(5.94 \AA)$ and $\mathbf{T h B B}^{\mathbf{4}}$ (6.10 $\mathrm{A})$, which were deduced from the crystal structures, may not be all that accurate as a consequence of the disorder. In general, these solid-state structures, however, do provide some clues when it comes to interpreting the trend in the host-guest association constants obtained from titration experiments in their reduced states. Since the cavity sizes of $\mathbf{D T h} \mathbf{B B}^{\mathbf{4}^{+}}(5.8 \AA)$ and $\mathbf{B B}^{\mathbf{4 +}}$ $(6.8 \AA)$ are either $c a$. $0.5 \AA$ smaller or larger than $6.3 \AA$, their binding constants when reduced to bisradical dications for hosting $\mathbf{M V}^{+\bullet}$ are quite similar, i.e., $(6.7 \pm 3.8) \times 10^{4}$ vs. $(3.9 \pm 0.5)$ $\left.\times 10^{4} \mathbf{M}^{-1}\right)$. The asymmetric $\mathbf{T h B B}{ }^{4+}$, which can be regarded as an

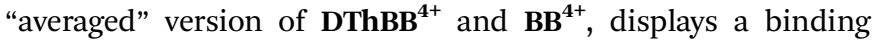
constant $(1.7 \pm 0.6) \times 10^{4} \mathbf{M}^{-1}$ for $[\mathbf{M V} \subset \mathbf{T h B B}]^{3(\cdot+)}$ that is higher than those for both $[\mathbf{M V} \subset \mathbf{D T h B B}]^{3(\cdot+)}$ and $[\mathbf{M V} \subset \mathbf{B B}]^{3(\cdot+)}$. The other two cyclophanes, $\mathbf{P y B B}^{\mathbf{4 +}}$ and $\mathbf{m p B B}{ }^{\mathbf{4}}$, which have asymmetric constitutions and much smaller cavities, display much lower binding constants $\left((7.4 \pm 0.6) \times 10^{3} \mathrm{M}^{-1}\right.$ and $(8.9 \pm 1.3) \times$ $10^{3} \mathbf{M}^{-1}$, respectively) for $[\mathbf{M V} \subset \mathbf{P y B B}]^{3(\cdot+)}$ and $[\mathbf{M V} \subset \mathbf{m p B B}]^{3(\cdot+)}$. When the cavity size is decreased even further, as in the case of $\mathbf{m B B}^{\mathbf{4 +}}$ (5.26 $\AA$ ) with its two $m$-xylylene spacers (Scheme 1 ), no binding towards $\mathbf{M V}^{{ }^{+}}$in its reduced state was observed either in solution or in the solid state.
We also obtained the crystal structures of the bisradical dicationic forms of the cyclophanes, $\mathbf{D T h B B}{ }^{2(\cdot+)}, \mathbf{T h B B}^{2(\cdot+)}$, and mpBB ${ }^{2(\cdot+)}$, while $\mathbf{P y B B}^{2(\cdot+)}$ failed to form single crystals suitable enough for X-ray crystallography. Again, disorder also plagued (Fig. $4 \mathrm{~b}$ and $\mathrm{S} 13 \dagger$ ) the crystal structure of $\mathbf{T h B B}^{2(\cdot+)}$ on account of its having two different linkers. No disorder, however, was observed in the case of the other asymmetric cyclophane mpBB ${ }^{2(\cdot)}$. Notably, all three bisradical dicationic cyclophanes formed (Fig. 4, S11-S13†) one-dimensional stacked columns in the solid state on account of intermolecular radical-radical interactions between adjacent BIPY $^{*+}$ units, in a manner similar to that already reported ${ }^{8}$ for $\mathbf{B B}^{2(\cdot+)}$, with distances (Fig. 4) between stacked BIPY ${ }^{+}$units in neighbouring bisradical dicationic cyclophanes of $3.36,3.09$ and $3.11 \AA$ for $\mathbf{m p B B}^{2(\cdot+)}$, $\mathbf{D T h B B}^{2(\cdot+)}$ and $\mathbf{T h B B}^{2(\cdot+)}$, respectively. Consequently, these bisradical dicationic cyclophanes display significantly longer centroid-to-centroid BIPY ${ }^{*+}$ distances than the corresponding BIPY $^{2+}$ distances (Fig. 3 and Table 1) in the tetracationic cyclophanes in their solid states, most likely as a result of the strong intermolecular radical-radical interactions enlarging the cavities of the bisradical dicationic cyclophanes in the solid states. In solution, however, the intermolecular stacking interactions between bisradical dicationic cyclophanes will be negligible, and the solution-phase cavity sizes are expected to be smaller than those observed in their solid states.

Finally, density functional theory (DFT) calculations using B3LYP basis set with D3 dispersion correction ${ }^{20}$ were conducted in order to investigate the binding energies of the trisradical tricationic complexes. The optimised structures of the bisradical dicationic hosts were optimised (Fig. S18†) showing that the predicted cavity sizes-centroid-to-centroid distances between BIPY $^{*+}$ units-are in better agreement (Table 1) with the measured distances in the tetracationic cyclophanes in the solid state than those of the bisradical dicationic cyclophanes. The calculations predict (Table 1 and Fig. 5b) the host-guest binding energies to be in the order of $\left|\Delta E_{\mathrm{ThBB}}\right|<\left|\Delta E_{\mathrm{BB}}\right|<\left|\Delta E_{\mathrm{DThBB}}\right|<$ $\left|\Delta E_{\mathrm{mpBв}}\right|<\left|\Delta E_{\mathrm{PyBв}}\right|$ in agreement with the experimental results. The binding energies with $\mathbf{M V}^{*+}$ exhibit strong dependences on

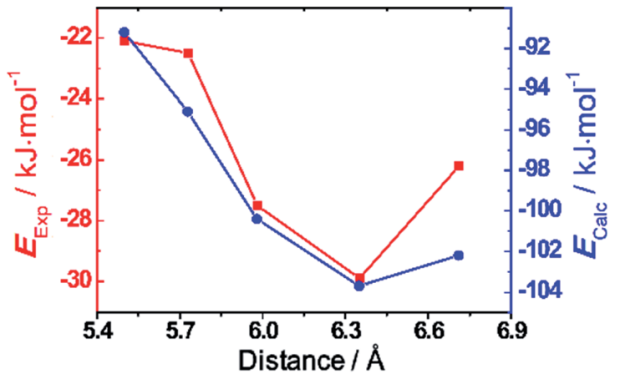

Fig. 5 Binding energies ( $y$ axis) towards $\mathrm{MV}^{\cdot+}$ for the five cyclophanes with different cavity sizes (centroid-to-centroid distances between the two BIPY ${ }^{++}$units, $x$ axis). The $x$ axis presents the DFT-calculated centroid-to-centroid distances ${ }^{22}$ between the two BIPY ${ }^{\cdot+}$ units. The left red $y$ axis indicates the experimental binding energies towards binding with $\mathrm{MV}^{\cdot+}$ from vis/NIR titration, while the right blue axis presents the DFT-calculated binding energies towards binding with $\mathrm{MV}^{\cdot+}$ 
the cyclophane cavity sizes. In an attempt to analyse the correlations between the cavity sizes and the binding energies, we decomposed (Table S2 $\dagger$ ) the binding energies into the contributions $^{21}$ from dispersion and electrostatic energies. The attractive dispersion interactions (Table S2†) weaken with increasing with host size, while the concomitant decrease (Table S2 $\dagger$ ) in electrostatic repulsion stabilises host-guest binding. Thus, it is the competition between the two counteracting interactions which results in the optimal host-guest binding (Fig. 5) at a cavity size of $c a .6 .3 \AA$, i.e., as exemplified by ThBB $^{2(\cdot+)}$.

\section{Conclusions}

Four bisradical dicationic cyclophanes were investigated as hosts for binding $\mathbf{M V}^{++}$and found to form trisradical triscationic complexes. UV-vis-NIR titration experiments, X-ray crystallographic characterizations and DFT calculations revealed that the binding affinities of these trisradical triscationic complexes are highly dependent on the cavity sizes of the bisradical dicationic cyclophanes. The structure-property relationship we have established will provide useful information for the design of new radical host-guest pairs in the future. Notably, the asymmetric $p$-xylylene/2,5-thiophene-dimethyl linked cyclophane $\mathbf{T h B B}^{2(+\cdot)}$ which displayed an association constant of $170000 \mathrm{M}^{-1}$ in acetonitrile, that is 4.3 times higher than that $\left(39000 \mathbf{M}^{-1}\right)$ of $\mathbf{B B}^{2(+\cdot)}$ which has two $p$-xylylene linkers. The facile accessibility, tunable association constants, as well as decreased host cavity sizes associated with these four new trisradical tricationic complexes, make them attractive redox-controlled recognition motifs for further use in supramolecular chemistry and in the template-directed synthesis of mechanically interlocked molecules.

\section{Conflicts of interest}

There are no conflicts to declare.

\section{Acknowledgements}

This research is part of the Joint Center of Excellence in Integrated Nano-Systems (JCIN) at King Abdulaziz City for Science and Technology (KACST) and Northwestern University (NU). The authors thank both KACST and NU for their continued support of this research. This work utilized Northwestern University Micro/Nano Fabrication Facility (NUFAB), which is partially supported by the Soft and Hybrid Nanotechnology Experimental (SHyNE) Resource (NSF ECCS-1542205), the Materials Research Science and Engineering Center (DMR1720139), the State of Illinois, and Northwestern University.

\section{Notes and references}

1 (a) D. C. Sherrington and K. A. Taskinen, Chem. Soc. Rev., 2001, 30, 83-93; (b) K. Tashiro and T. Aida, Chem. Soc. Rev., 2007, 36, 189-197; (c) Z. J. Chen, A. Lohr, C. R. Saha-Möller and F. Würthner, Chem. Soc. Rev., 2009, 38, 564-584; (d)
X. Zhang and C. Wang, Chem. Soc. Rev., 2011, 40, 94-101; (e) Y. R. Zheng and P. J. Stang, Chem. Rev., 2013, 113, 734777; $(f)$ M. M. Watt, M. S. Collins and D. W. Johnson, Acc. Chem. Res., 2013, 46, 955-966; (g) Q. Yan, Z. Luo, K. Cai, Y. Ma and D. Zhao, Chem. Soc. Rev., 2014, 43, 4199-4221.

2 For reviews on radical-radical interactions between conjugated radical cations or anions, see: (a) D. W. Zhang, J. Tian, L. Chen, L. Zhang and Z.-T. Li, Chem.-Asian J., 2015, 10, 56-68; (b) L. Chen, Y.-C. Zhang, W.-K. Wang, J. Tian, L. Zhang, H. Wang, D.-W. Zhang and Z.-T. Li, Chin. Chem. Lett., 2015, 26, 811-816.

3 (a) E. M. Fatila, R. A. Mayo, M. Rouzieres, M. C. Jennings, P. Dechambenoit, D. V. Soldatov, C. Mathoniere, R. Clerac, C. Coulon and K. E. Preuss, Chem. Mater., 2015, 27, 40234032; (b) X. Zheng, Y. Zhang, N. Cao, X. Li, S. Zhang, R. Du, H. Wang, Z. Ye, Y. Wang, F. Cao and H. Li, Nat. Commun., 2018, 9, 1961; (c) B. Tang, W.-L. Li, Y. Chang, B. Yuan, Y. Wu, M.-T. Zhang, J.-F. Xu, J. Li and X. Zhang, Angew. Chem., Int. Ed., 2019, 58, 15526-15531.

4 (a) J. W. Park, N. H. Choi and J. H. Kim, J. Phys. Chem., 1996, 100, 769-774; (b) W. S. Jeon, H.-J. Kim, C. Lee and K. Kim, Chem. Commun., 2002, 1828-1829; (c) A. Iordache, M. Oltean, A. Milet, F. Thomas, B. Baptiste, E. Saint-Aman and C. Bucher, J. Am. Chem. Soc., 2012, 134, 2653-2671; (d) A. T. Buck, J. T. Paletta, S. A. Khindurangala, C. L Beck and A. H. Winter, J. Am. Chem. Soc., 2013, 135, 10594-10597; (e) L. Zhang, T.-Y. Zhou, J. Tian, H. Wang, D.-W. Zhang, X. Zhao, Y. Liu and Z.-T. Li, Polym. Chem., 2014, 5, 47154721.

5 (a) E. M. Kosower and J. Hajdu, J. Am. Chem. Soc., 1971, 93, 2534-2535; (b) W. Geuder, S. Hünig and A. Suchy, Tetrahedron, 1986, 42, 1665-1677.

6 B. Odell, M. V. Reddington, A. M. Slawin, N. Spencer, J. F. Stoddart and D. J. Williams, Angew. Chem., Int. Ed. Engl., 1988, 27, 1547-1550.

7 A. Trabolsi, N. Khashab, A. C. Fahrenbach, D. C. Friedman, M. T. Colvin, K. K. Cotí, D. Benítez, E. Tkatchouk, J.-C. Olsen, M. E. Belowich, R. Carmielli, H. A. Khatib, W. A. Goddard III, M. R. Wasielewski and J. F. Stoddart, Nat. Chem., 2010, 2, 42-49.

8 (a) A. C. Fahrenbach, J. C. Barnes, D. A. Lanfranchi, H. Li, A. Coskun, J. J. Gassensmith, Z. Liu, D. Benítez, A. Trabolsi, W. A. Goddard III, M. Elhabiri and J. F. Stoddart, J. Am. Chem. Soc., 2012, 134, 3061-3072; (b) C. Cheng, T. Cheng, H. Xiao, M. D. Krzyaniak, Y. Wang, P. R. McGonigal, M. Frasconi, J. C. Barnes, A. C. Fahrenbach, M. R. Wasielewski, W. A. Goddard III and J. F. Stoddart, J. Am. Chem. Soc., 2016, 138, 8288-8300.

9 (a) H. Li, A. C. Fahrenbach, S. K. Dey, S. Basu, A. Trabolsi, Z. Zhu, Y. Y. Botros and J. F. Stoddart, Angew. Chem., Int. Ed., 2010, 49, 8260-8265; (b) J. C. Barnes, A. C. Fahrenbach, D. Cao, S. M. Dyar, M. Frasconi, M. A. Giesener, D. Benítez, E. Tkatchouk, O. Chernyashevskyy, W. H. Shin, H. Li, S. Sampath, C. L. Stern, A. A. Sarjeant, K. J. Hartlieb, Z. Liu, R. Carmieli, Y. Y. Botros, J. W. Choi, A. M. Z. Slawin, 
J. B. Ketterson, M. R. Wasielewski, W. A. Goddard III and J. F. Stoddart, Science, 2013, 339, 429-433.

10 (a) C. J. Bruns, M. Frasconi, J. Iehl, K. J. Hartlieb, S. T. Schneebeli, C. Cheng, S. I. Stupp and J. F. Stoddart, J. Am. Chem. Soc., 2014, 136, 4714-4723; (b) C. Cheng, P. R. McGonigal, S. T. Schneebeli, H. Li, N. A. Vermeulen, C. Ke and J. F. Stoddart, Nat. Nanotechnol., 2015, 10, 547553.

11 (a) J. Deng, N. Song, Q. Zhou and Z. Su, Org. Lett., 2007, 26, 5393-5396; (b) A. Iordache, M. Oltean, A. Milet, F. Thomas, B. Baptiste, E. Saint-Aman and C. Bucher, J. Am. Chem. Soc., 2012, 134, 2653-2671; (c) C. Kahlfuss, S. DenisQuanquin, N. Calin, E. Dumont, M. Garavelli, G. Royal, S. Cobo, E. Saint-Aman and C. Bucher, J. Am. Chem. Soc., 2016, 138, 15234-15242.

12 (a) H. Li, Z. Zhu, A. C. Fahrenbach, B. M. Savoie, C. Ke, J. C. Barnes, J. Lei, Y.-L. Zhao, L. M. Lilley, T. J. Marks, M. A. Ratner and J. F. Stoddart, J. Am. Chem. Soc., 2013, 135, 456-467; (b) J. Sun, Z. Liu, W.-G. Liu, Y. Wu, Y. Wang, J. C. Barnes, K. R. Hermann, W. A. Goddard III, M. R. Wasielewski and J. F. Stoddart, J. Am. Chem. Soc., 2017, 139, 12704-12709.

13 (a) M. Berville, L. Karmazin, J. A. Wytko and J. Weiss, Chem. Commun., 2015, 51, 15772-15775; (b) M. Berville, S. Choua, C. Gourlaouen, C. Boudon, L. Ruhlmann, C. Bailly, S. Cobo, E. Saint-Aman, J. Wytko and J. Weiss, ChemPhysChem, 2017, 18, 796-803; (c) K. Cai, M. C. Lipke, Z. Liu, J. Nelson, T. Cheng, Y. Shi, C. Cheng, D. Shen, J.-M. Han, S. Vemuri, Y. Feng, C. L. Stern, W. A. Goddard III, M. R. Wasielewski and J. F. Stoddart, Nat. Commun., 2018, 9, 5275.

14 A bolded descriptor denotes a compound, be it free or complexed, and an unbolded descriptor refers to either (i) a component within a molecule or (ii) a component part of a mechanically interlocked molecule.

15 M. B. Nielsen, J. G. Hansen and J. Becher, Eur. J. Org. Chem., 1999, 11, 2807-2815.

16 H. Scheytza, O. Rademacher and H. -U. Reißig, Eur. J. Org. Chem., 1999, 9, 2373-2381.

17 P. R. Ashton, J. A. Preece, J. F. Stoddart, M. S. Tolley, A. J. P. White and D. J. Williams, Synthesis, 1994, 12, 13441352.

18 J. C. Barnes, M. Juríček, N. A. Vermeulen, E. J. Dale and J. F. Stoddart, J. Org. Chem., 2013, 78, 11962-11969.

19 (a) H. J. Schneider, D. Guettes and U. Schneider, J. Am. Chem. Soc., 1988, 110, 6449-6454; (b) C. E. Chang and M. K. Gilson, J. Am. Chem. Soc., 2004, 126, 13156-13164; (c) Y. Shi, K. Cai, H. Xiao, Z. Liu, J. Zhou, D. Shen, Y. Qiu, Q.-H. Guo, C. L. Stern, M. R. Wasielewski, F. Diederich, W. A. Goddard III and J. F. Stoddart, J. Am. Chem. Soc., 2018, 140, 13835-13842.

20 (a) J. P. Perdew, K. Burke and M. Ernzerhof, Phys. Rev. Lett., 1996, 77, 3865-3868; (b) S. Grimme, S. Ehrlich and L. Goerigk, J. Comput. Chem., 2011, 32, 1456-1465.

21 M. R. Geraskina, A. S. Dutton, M. J. Juetten, S. A. Wood and A. H. Winter, Angew. Chem., Int. Ed., 2017, 56, 9435-9439.

22 All the four bisradical dicationic cyclophanes have strong intermolecular radical-radical interactions in the solid states, enlarging their cavity sizes significantly. Disorder plagued the crystal structures of the asymmetric PyBB4 ${ }^{+}$ and $\mathbf{T h B B 4}^{+}$, making it difficult to determine their cavity sizes accurately. Therefore, DFT-calculated cavity sizes for these bisradical dicationic cyclophanes are probably a better basis for estimating their real cavity sizes. 